\title{
Composition Design and Fatigue Curves of Hardfacing Materials for Cold Roll
}

\author{
C. L. Chen, ${ }^{1,2}$ C. X. Chen, ${ }^{1,2}$ Z. H. Guo, ${ }^{1}$ J. Ding, ${ }^{1,2}$ X. Han, ${ }^{1}$ and Q. Jiang ${ }^{1}$ \\ ${ }^{1}$ School of Materials Science and Engineering, Hebei University of Technology, Tianjin 300132, China \\ ${ }^{2}$ Tianjin Key Laboratory of Materials Laminating Fabrication and Interface Control Technology, Tianjin 300132, China \\ Correspondence should be addressed to C. X. Chen; karenccx@126.com
}

Received 30 November 2015; Revised 4 February 2016; Accepted 7 February 2016

Academic Editor: Sheng-Rui Jian

Copyright (c) 2016 C. L. Chen et al. This is an open access article distributed under the Creative Commons Attribution License, which permits unrestricted use, distribution, and reproduction in any medium, provided the original work is properly cited.

\begin{abstract}
In order to improve the fatigue life of cold rolls, a series of hardfacing alloys were designed by orthogonal experiments considering the interaction between carbon, chromium, and niobium. Hardfacing layers were produced by Tungsten Inert Gas (TIG) arc welding. The effects of alloy content on microstructure and carbides and fatigue behavior at different load frequency and different temperature were analyzed. The results show that suitable combination of $0.5 \% \mathrm{C}, 4.0 \% \mathrm{Cr}$, and $2.0 \% \mathrm{Nb}$ can obtain a high hardness of $54.7 \mathrm{HRC}$ for the formation of fine lath martensite and carbides with dispersed distribution. The new designed hardfacing materials have similar $\Delta \varepsilon-N$ curves with parent material in low load frequency and below $400^{\circ} \mathrm{C}$.
\end{abstract}

\section{Introduction}

The widely used backup rolls in industrial production always endure cycle load at high temperature during rolling process [1]. Therefore, subsurface cracks can form for the contact fatigue and then propagate to surface resulting in spalling $[2$, $3]$. In order to improve the mechanical properties of roll surface and avoid material waste for the replacement of new rolls, overlaying welding is usually used to develop surface layers, which make considerable contributions to high productivity, high product quality, extended roll life, and low material cost $[4,5]$.

Hardfacing should be a material selected for high hardness and good microstructural and for strength and economy [6]. There are many kinds of hardfacing alloy systems including cobalt-based, nickel-based, copper-based, and iron-based alloys. Fe-based alloys are considered as one of the most promising alloys for their high bonding strength, high hardness, excellent mechanical properties, and lower cost than cobalt-based and nickel-based overlaying, so it has drawn more and more attention in recent years [7].

Carbides such as chromium carbide and tungsten carbide are very important strengthening phases in hardfacing layer and used widely in hardfacing materials. However, the hardfacing layer must have higher fatigue resistance to avoid spalling failure, which requires that hardfacing layer must have a good match of hardness and toughness. So multialloy system is adopted to solve this problem. Except chromium and tungsten, strong carbide forming alloy elements such as niobium and titanium are added in hardfacing materials to gain hard MC type carbides. As one of the most effective hard particles, MC carbides are sphere and short rods in shape and the hardness is up to 2000 3000 HV which will strengthen the hardfacing layer. Moreover, the carbides of niobium and titanium can effectively refine microstructure by pinning grain boundary [7-9] and be helpful for the improvement of toughness [10].

The purpose of this research is to control the type and quantity of carbides and predict fatigue curves of rolls under the condition of high temperature and different load frequency. New hardfacing materials with different content match of carbon, chromium, and niobium were developed with good match of strength and toughness. In addition, load frequency and temperature effects on hardfacing material were investigated compared with $9 \mathrm{Cr} 2 \mathrm{Mo}$. 
TABLE 1: Chemical composition of hardfacing materials (wt\%).

\begin{tabular}{lccccccc}
\hline $\mathrm{C}$ & $\mathrm{Si}$ & $\mathrm{Mn}$ & $\mathrm{Cr}$ & $\mathrm{Mo}$ & $\mathrm{W}+\mathrm{V}+\mathrm{Ti}$ & $\mathrm{Nb}$ & $\mathrm{Fe}$ \\
\hline $0.3-0.5$ & 0.5 & 1.5 & $3.0-5.0$ & $\leq 2.0$ & $\leq 2.1$ & $2.0-6.0$ & $\mathrm{Bal}$ \\
\hline
\end{tabular}

\section{Experiment and Calculation Method}

2.1. Experimental Procedure. Three factors and three-level orthogonal experiments were adopted to design the hardfacing materials. The interactions between carbon, chromium, and niobium were considered in this study. The composition of hardfacing material is shown in Table 1.

The hardfacing materials were deposited on low carbon steel using the Tungsten Inert Gas Welding Technology. In order to gain undiluted layer, the thickness of hardfacing layers was approximately $8 \mathrm{~mm}$.

The hardness was tested by Rockwell hardness testing machine. All specimens were etched with a solution of $4 \%$ nital. Microstructure examination of the specimens was carried out by Olycia M3 optical microscopy (OM) and Nova Nano SEM450s scanning electron microscopy. XPertMPD Xray diffractometer was used to analyze carbides.

2.2. Fatigue Curves Calculation. The $S-N$ relationship of materials can be obtained using fatigue test [11]. However a lot of money and time will be spent. So calculating fatigue curves has great advantages. JMatPro, a multiplatform software program for the prediction of the properties of multicomponent alloys, was used to analyze the fatigue property ( $\Delta \varepsilon-N$ curves) of hardfacing materials.

In this method, a relationship between monotonic tensile properties and uniaxial fatigue properties was developed first and then combined high temperature properties (Young's modulus and strength) to evaluate the fatigue curves of the material. The relationship between the strain range $\Delta \varepsilon$ and subsequent fatigue life $N$ is usually given by the classical Coffin-Manson Equation:

$$
\begin{aligned}
& \frac{\Delta \varepsilon}{2}=\frac{\Delta \varepsilon_{e}}{2}+\frac{\Delta \varepsilon_{p}}{2}=\frac{\Delta \sigma}{2 E}+\left(\frac{\Delta \sigma}{2 K^{\prime}}\right)^{1 / n^{\prime}}, \\
& \frac{\Delta \varepsilon}{2}=\frac{\Delta \varepsilon_{e}}{2}+\frac{\Delta \varepsilon_{p}}{2}=\frac{\sigma_{f}^{\prime}}{E}(2 N)^{b}+\varepsilon_{f}^{\prime}(2 N)^{c},
\end{aligned}
$$

in which $\Delta \varepsilon$ is total strain range in axial fatigue test; $\Delta \varepsilon_{e}$ is elastic strain range in axial fatigue test; $\Delta \varepsilon_{p}$ is plastic strain range in axial fatigue test; $N$ is number of cycles to failure; $\sigma_{f}^{\prime}$ is axial fatigue strength coefficient; $\varepsilon_{f}^{\prime}$ is axial fatigue ductility coefficient; $b$ is axial fatigue strength exponent; $c$ is axial fatigue ductility exponent; $n^{\prime}$ is cyclic strain hardening exponent; $K^{\prime}$ is cyclic strain hardening coefficient.

The two equations are usually used to describe the cyclic stress-strain behavior and strain-life relationship [12].

\section{Results}

3.1. Hardness. Table 2 and Figure 1 give the hardness results of orthogonal experiments. It can be seen that carbon is
TABLE 2: Hardness of different samples.

\begin{tabular}{lcccc}
\hline & $\mathrm{C}(\mathrm{wt} \%)$ & $\mathrm{Cr}(\mathrm{wt} \%)$ & $\mathrm{Nb}(\mathrm{wt} \%)$ & Hardness (HRC) \\
\hline 1 & 0.3 & 3.0 & 2.0 & 42.3 \\
2 & 0.3 & 4.0 & 4.0 & 6.8 \\
3 & 0.3 & 5.0 & 6.0 & 14.5 \\
4 & 0.4 & 3.0 & 4.0 & 40.0 \\
5 & 0.4 & 4.0 & 6.0 & 8.2 \\
6 & 0.4 & 5.0 & 2.0 & 50.0 \\
7 & 0.5 & 3.0 & 6.0 & 41.9 \\
8 & 0.5 & 4.0 & 2.0 & 54.7 \\
9 & 0.5 & 5.0 & 4.0 & 50.4 \\
$T_{1 j}$ & 63.6 & 124.2 & 147 & \\
$T_{2 j}$ & 98.2 & 69.7 & 97.2 & \\
$T_{3 j}$ & 147 & 114.9 & 64.6 & \\
$M_{1 j}$ & 21.2 & 41.4 & 49 & \\
$M_{2 j}$ & 32.73 & 23.23 & 32.4 & \\
$M_{3 j}$ & 49 & 38.3 & 21.53 & \\
$R_{j}$ & 27.8 & 18.17 & 27.47 & \\
\hline
\end{tabular}

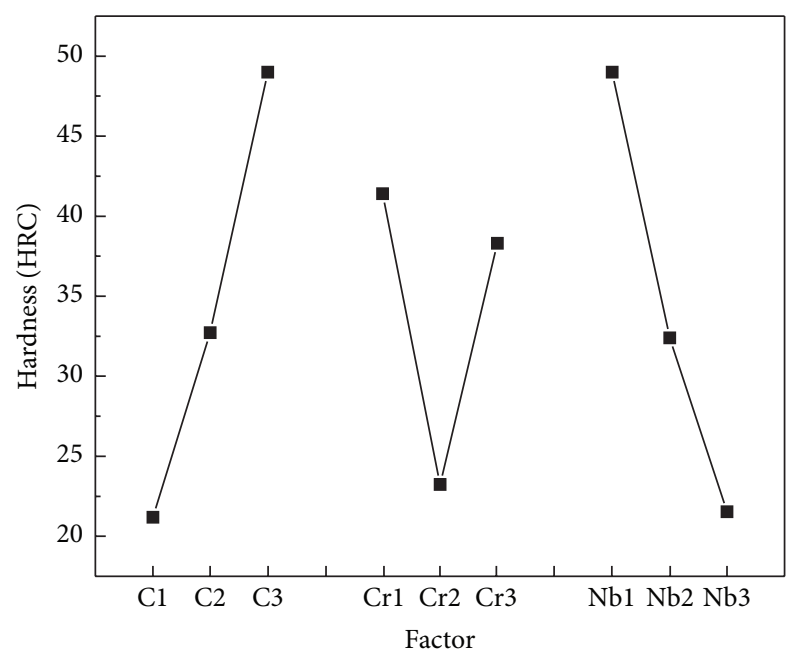

FIGURE 1: Relationship between hardness and factors.

the most effective factor for the hardfacing hardness and the least is chromium. Moreover, the hardness is improved with the increasing of carbon content and the decrease of niobium content. However, the hardness exhibited a drop and then rise with the increase of chromium content. This is related to the carbon redistribution and carbides content [4]. As a strong carbide forming element, niobium carbides will precipitate first at high temperature stage. The higher the niobium content is, the lower the content of carbon in matrix and chromium carbides is and the lower the hardness is. According to the thermodynamic equilibrium calculation, the average mass fraction of $\mathrm{NbC}$ is $3.88 \%, 3.31 \%$, and $3.45 \%$ in the level of $3.0 \% \mathrm{Cr}, 4.0 \% \mathrm{Cr}$, and $5.0 \% \mathrm{Cr}$, respectively. As $\mathrm{NbC}$ has significant effect on hardness, the hardness exhibited a drop and then rise with the increasing chromium content. Through the analysis of Figure 1, 0.5\% C, 3.0\% Cr, and 2.0\% 


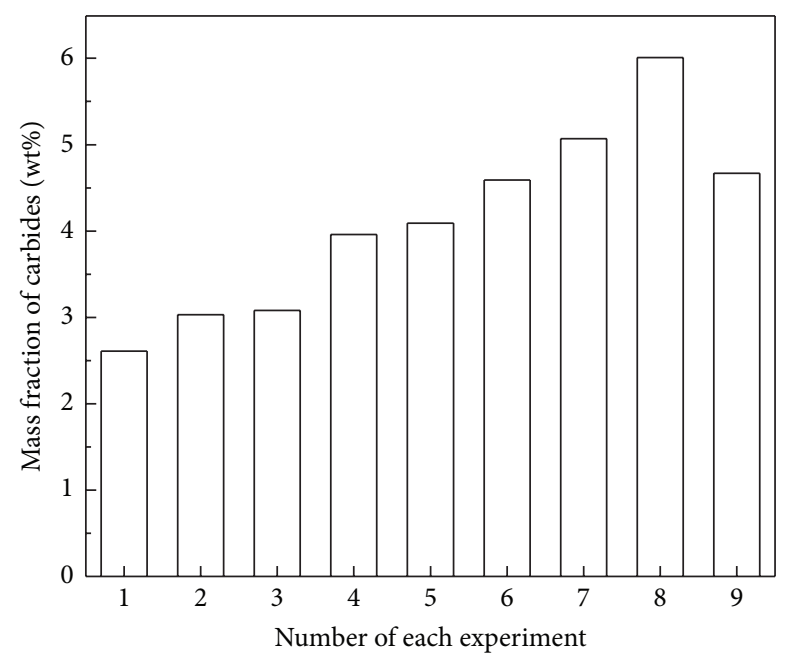

FIGURE 2: Mass fraction of carbides.

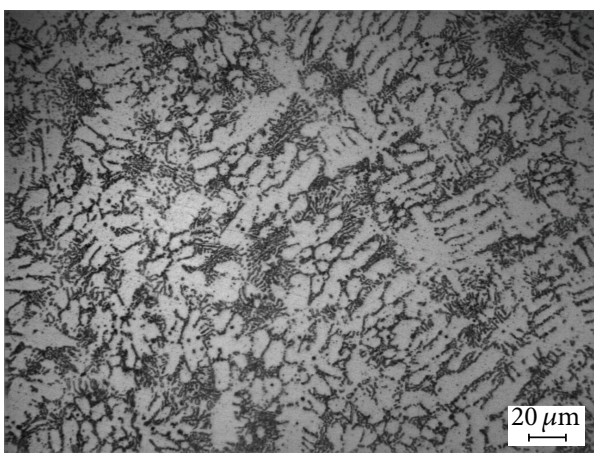

(a)

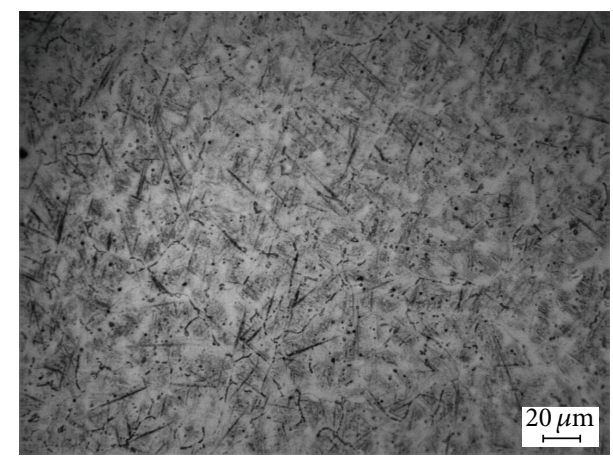

(b)

Figure 3: Microstructure of hardfacing layer of (a) alloy 2 and (b) alloy 8.

$\mathrm{Nb}$ appear to be an optimum composition for the improved Rockwell hardness.

Table 2 also shows that hardness changes evidently for the samples with different content match of carbon, chromium, and niobium. This contributes to carbides type and content (as shown in Figure 2). Under the condition of certain carbon content, the ratio of $\mathrm{Cr} / \mathrm{Nb}$ is very important to the hardness. For alloy 1 with higher $\mathrm{Cr} / \mathrm{Nb}$ ratio 1.5 , the hardness is 42.3 HRC. But the hardness decreases evidently for alloys 2 and 3 with lower $\mathrm{Cr} / \mathrm{Nb}$ ratio. The same phenomenon can be seen for samples with carbon content of $0.4 \%$ and $0.5 \%$. Alloy 8 with $0.5 \% \mathrm{C}$ and $2.0 \mathrm{Cr} / \mathrm{Nb}$ ratio has the highest hardness for its higher carbides content. It indicates that the good match of $\mathrm{C}, \mathrm{Cr}$, and $\mathrm{Nb}$ is crucial to achieve a hard matrix with a large fraction of carbides.

For the same chromium content, the interactions between carbon and niobium influence the hardness dramatically. The hardness of alloy 2 and alloy 8 with $4.0 \% \mathrm{Cr}$ is $6.8 \mathrm{HRC}$ and 54.7 HRC, respectively, for the different content of $\mathrm{C}$ and $\mathrm{Nb}$. The microstructure of alloy 2 is composed of ferrite and carbides for the low carbon content and higher niobium content, as shown in Figure 3(a). The carbides mainly consist of $\mathrm{NbC}$ and $\mathrm{TiC}$ (as shown in Figure 5(a)) and are distributed in grain boundary (as shown in Figure 4(a)). This is because niobium is the element to reduce the $\gamma$ phase which is helpful for the formation of ferrite. In addition as a strong carbide forming element [7], $\mathrm{NbC}$ will precipitate first and inhibit the formation of chromium carbides.

For alloy 8 with higher carbon content and lower niobium, the microstructure is composed of fine lath martensite and dispersed carbides ( $\mathrm{NbC}$ and $\mathrm{Cr} 7 \mathrm{C} 3$ ) (as shown in Figures 3(b), 4(b), and 5(b)) which contributed to the excellent hardness [4].

3.2. $\Delta \varepsilon-N$ Curves. Considering the service environment of cold rolls, load frequency and temperature have great effect on fatigue performance. In order to evaluate the fatigue life of new designed hardfacing materials $(0.5 \% \mathrm{C}, 3.0 \% \mathrm{Cr}$, and $2.0 \% \mathrm{Nb}$ ), a series of $\Delta \varepsilon-N$ curves at high temperature were calculated compared to $9 \mathrm{Cr} 2 \mathrm{Mo}$.

Figure 6 gives the $\Delta \varepsilon-N$ curves of alloy $9 \mathrm{Cr} 2 \mathrm{Mo}$ and the optimum new alloy in different load frequency at $400^{\circ} \mathrm{C}$. It can be seen that when the load frequency is $1 \mathrm{~Hz}$, the fatigue 


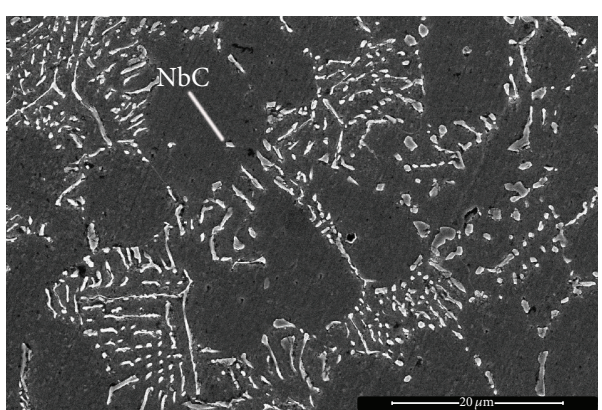

(a)

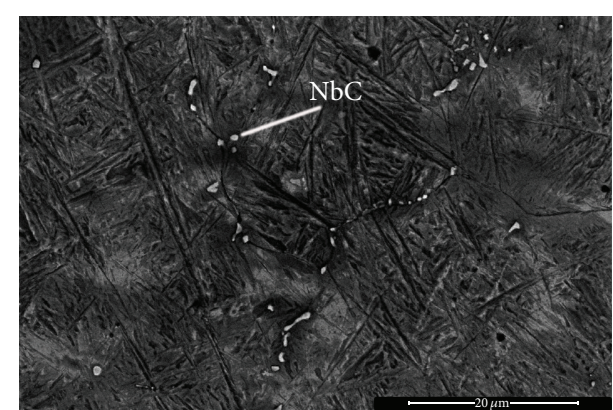

(b)

FIgURE 4: Carbides distribution: (a) alloy 2 and (b) alloy 8.

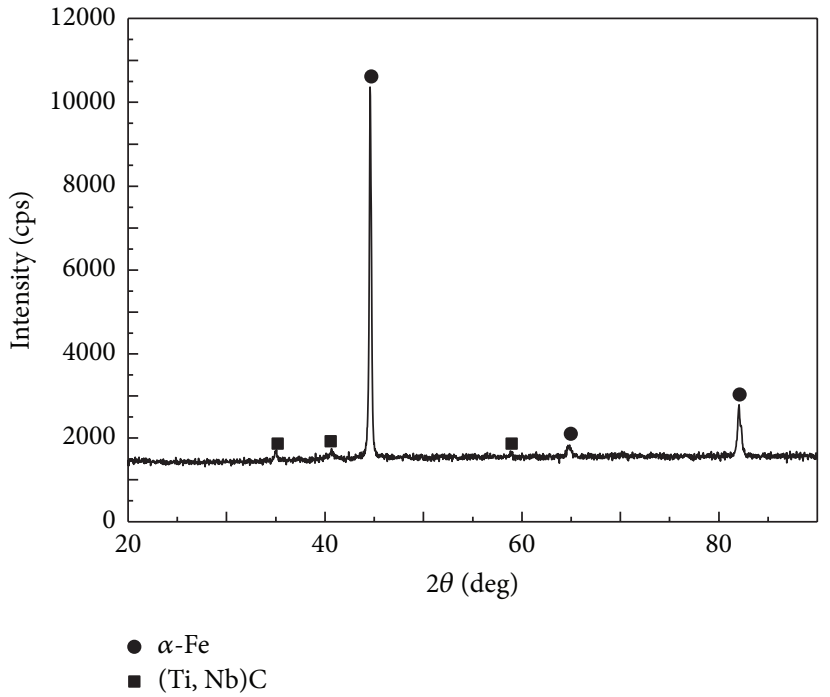

(a)

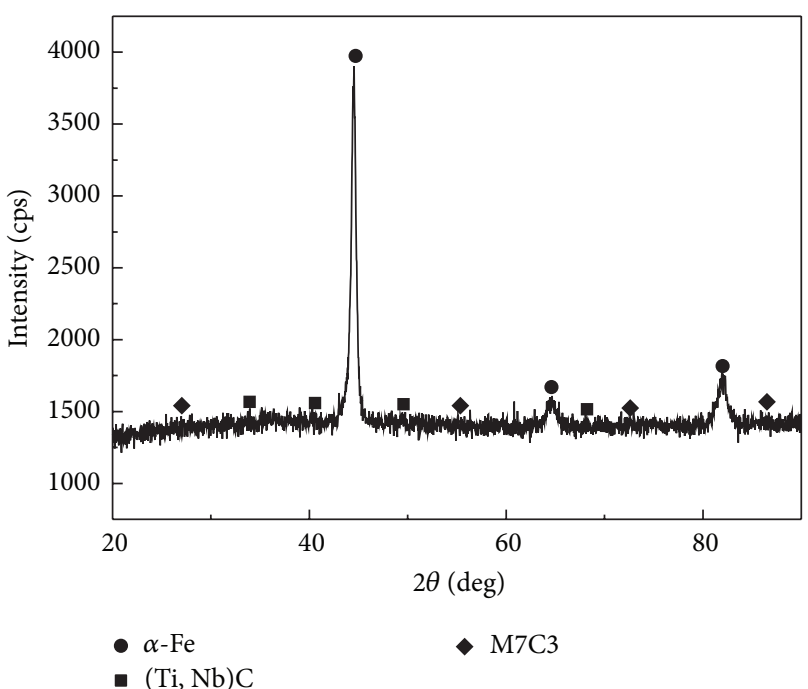

(b)

FIGURE 5: XRD results: (a) alloy 2 and (b) alloy 8.

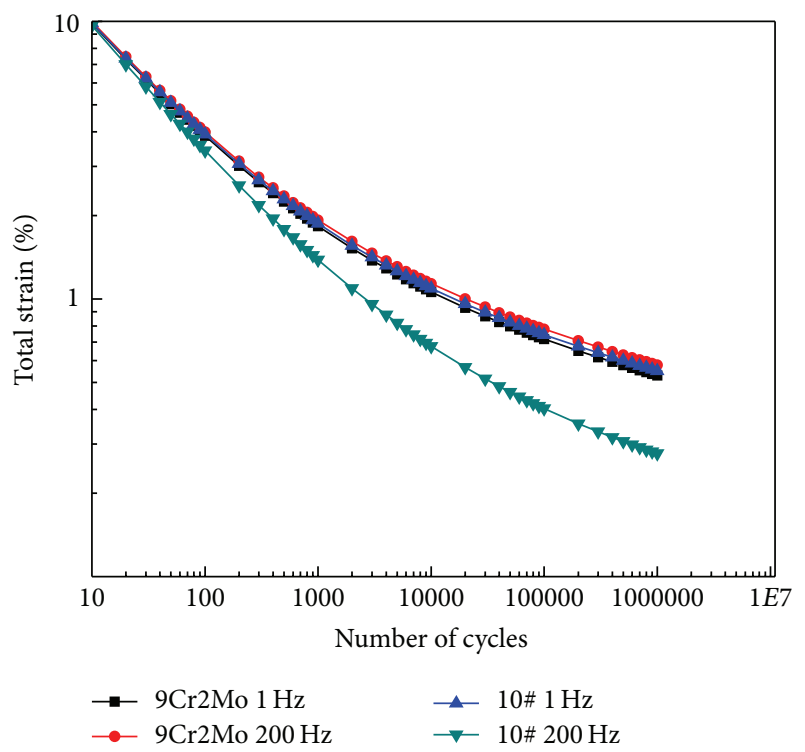

Figure 6: $\Delta \varepsilon-N$ curves of alloy $9 \mathrm{Cr} 2 \mathrm{Mo}$ and the optimum alloy (10\#) under different load frequency at $400^{\circ} \mathrm{C}$. curves of the two alloys are similar, which indicates that the hardfacing material (the optimum alloy) has the same fatigue properties with the roller matrix (alloy 9Cr2Mo) at low load frequency. The stable carbides and strength matrix maybe help for the excellent fatigue properties of hardfacing material. When the load frequency is $200 \mathrm{~Hz}$, fatigue behavior of the two alloys does not differ much below 100 cycles, but it differs dramatically above 10000 cycles, which illustrates that the strain capacities of the hardfacing material are not as good as the roll material in higher load frequency. The hardfacing material is more sensitive to the change of loading frequency than the roll material.

Figure 7 shows the effect of temperature on fatigue life. For $9 \mathrm{Cr} 2 \mathrm{Mo}$, fatigue property at $400^{\circ} \mathrm{C}$ is not better than that at $100^{\circ} \mathrm{C}$ at the load frequency of $100 \mathrm{~Hz}$. It manifests temperature has a small effect on the fatigue curves of $9 \mathrm{Cr} 2 \mathrm{Mo}$ when temperature is below $400^{\circ} \mathrm{C}$. Meanwhile, fatigue curves of the optimum alloy have little change when temperature ranges from $100^{\circ} \mathrm{C}$ to $400^{\circ} \mathrm{C}$, which illustrates that the hardfacing material has good strain capacities during high temperature. 


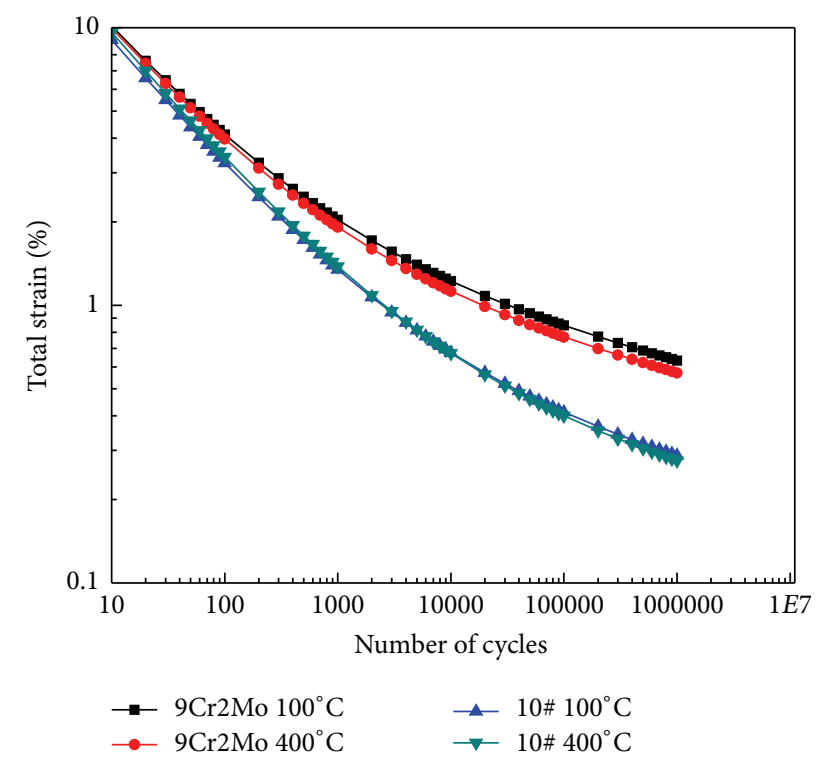

FIGURE 7: $\Delta \varepsilon$ - $N$ curves of alloy 9 Cr2Mo and the optimum alloy (10\#) at different temperature in $100 \mathrm{~Hz}$ load frequency.

\section{Conclusion}

New hardfacing materials with different carbon, chromium, and niobium content for cold rolls were designed by orthogonal experiments methods. The results show that the interaction between the three elements is critical for the hardness of hardfacing layer. Under the condition of certain carbon content, the increase of the $\mathrm{Cr} / \mathrm{Nb}$ ratio is helpful to increase hardness. For the condition of certain chromium content, the higher carbon content and lower niobium lead to higher hardness. When the chemical composition is $0.5 \% \mathrm{C}, 4.0 \%$ $\mathrm{Cr}$, and $2.0 \% \mathrm{Nb}$, the hardness is up to $54.7 \mathrm{HRC}$. This contributed to the fine lath martensite and dispersed distributed carbides.

$\Delta \varepsilon-N$ curves with different load frequency and temperature for 9Cr2Mo and the new designed alloy were calculated. Fatigue behavior of the optimum alloy is as good as that of $9 \mathrm{Cr} 2 \mathrm{Mo}$ at load frequency of $1 \mathrm{~Hz}$ and $400^{\circ} \mathrm{C}$.

\section{Conflict of Interests}

The authors declare that there is no conflict of interests regarding the publication of this paper.

\section{Acknowledgments}

This research is financially supported by the Nation Natural Science Foundation (no. 51304059) and China Scholarship Council (no. 201406705011).

\section{References}

[1] G. Pantazopoulos and A. Vazdirvanidis, "Fractographic and metallographic study of spalling failure of steel straightener rolls," Journal of Failure Analysis and Prevention, vol. 8, no. 6, pp. 509-514, 2008.
[2] H. R. B. Rad, A. Monshi, M. H. Idris, M. R. A. Kadir, and H. Jafari, "Premature failure analysis of forged cold back-up roll in a continuous tandem mill," Materials and Design, vol. 32, no. 89, pp. 4376-4384, 2011.

[3] X.-F. Qin, D.-L. Sun, L.-Y. Xie, and Q. Wu, "Hardening mechanism of Cr5 backup roll material induced by rolling contact fatigue," Materials Science \& Engineering A, vol. 600, pp. 195199, 2014.

[4] C. K. Kim, S. Lee, J.-Y. Jung, and S. Ahn, "Effects of complex carbide fraction on high-temperature wear properties of hardfacing alloys reinforced with complex carbides," Materials Science and Engineering A, vol. 349, no. 1-2, pp. 1-11, 2003.

[5] D. J. Branagan, M. C. Marshall, and B. E. Meacham, "High toughness high hardness iron based PTAW weld materials," Materials Science and Engineering A, vol. 428, no. 1-2, pp. 116123, 2006.

[6] B. Venkatesh, K. Sriker, and V. S. V. Prabhakar, "Wear characteristics of hardfacing alloys: state-of-the-art," Procedia Materials Science, vol. 10, pp. 527-532, 2015.

[7] X. H. Wang, F. Han, X. M. Liu, S. Y. Qu, and Z. D. Zou, "Microstructure and wear properties of the Fe-Ti-V-Mo-C hardfacing alloy," Wear, vol. 265, no. 5-6, pp. 583-589, 2008.

[8] E. O. Correa, N. G. Alcântara, L. C. Valeriano, N. D. Barbedo, and R. R. Chaves, "The effect of microstructure on abrasive wear of a Fe-Cr-C-Nb hardfacing alloy deposited by the open arc welding process," Surface \& Coatings Technology, vol. 276, pp. 479-484, 2015.

[9] A. V. Khvan, B. Hallstedt, and K. Chang, "Thermodynamic assessment of Cr-Nb-C and Mn-Nb-C systems," Calphad, vol. 39, pp. 54-61, 2012.

[10] Q. B. Wang, Z. X. Li, Y. W. Shi, L. Z. Wang, and F. Liu, "Interior crack and its formation mechanism in overlaying weld of backup rolls," Engineering Failure Analysis, vol. 34, pp. 268-277, 2013.

[11] C. S. Bandara, S. C. Siriwardane, U. I. Dissanayake, and R. Dissanayake, "Full range S-N curves for fatigue life evaluation of steels using hardness measurements," International Journal of Fatigue, vol. 82, part 2, pp. 325-331, 2016.

[12] Z. L. Guo, N. Saunders, P. Miodownik, and J.-P. Schille, "Modelling the strain-life relationship of commercial alloys," in Proceedings of the ASME Pressure Vessels and Piping Conference, pp. 281-287, San Antonio, Tex, USA, July 2007. 


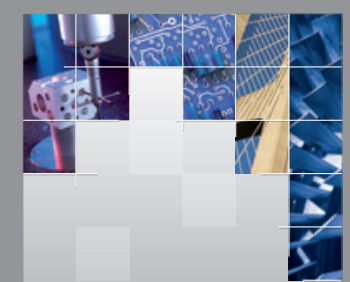

\section{Enfincering}
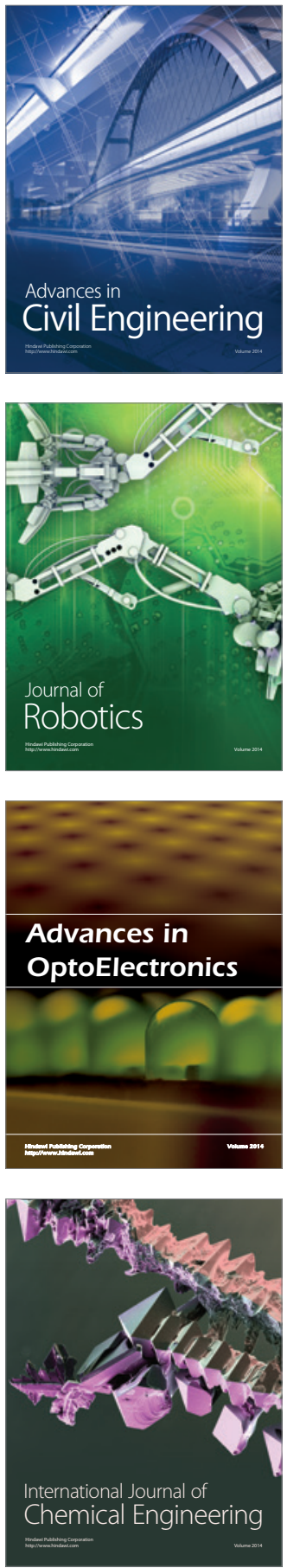

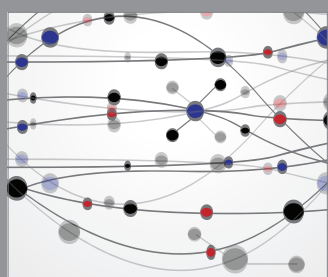

The Scientific World Journal

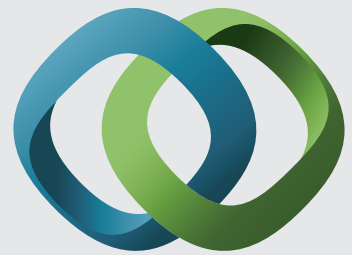

\section{Hindawi}

Submit your manuscripts at

http://www.hindawi.com
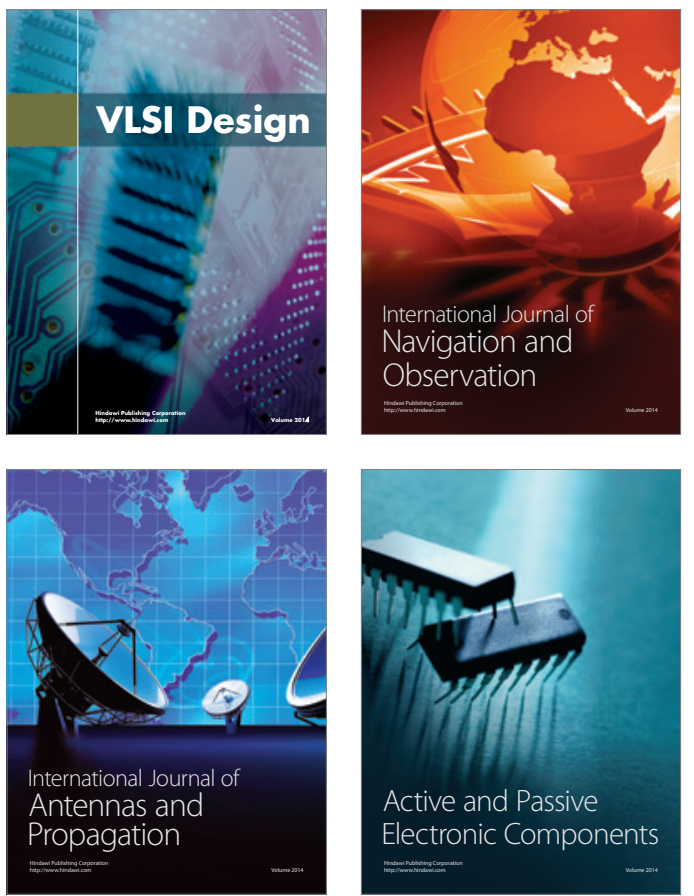
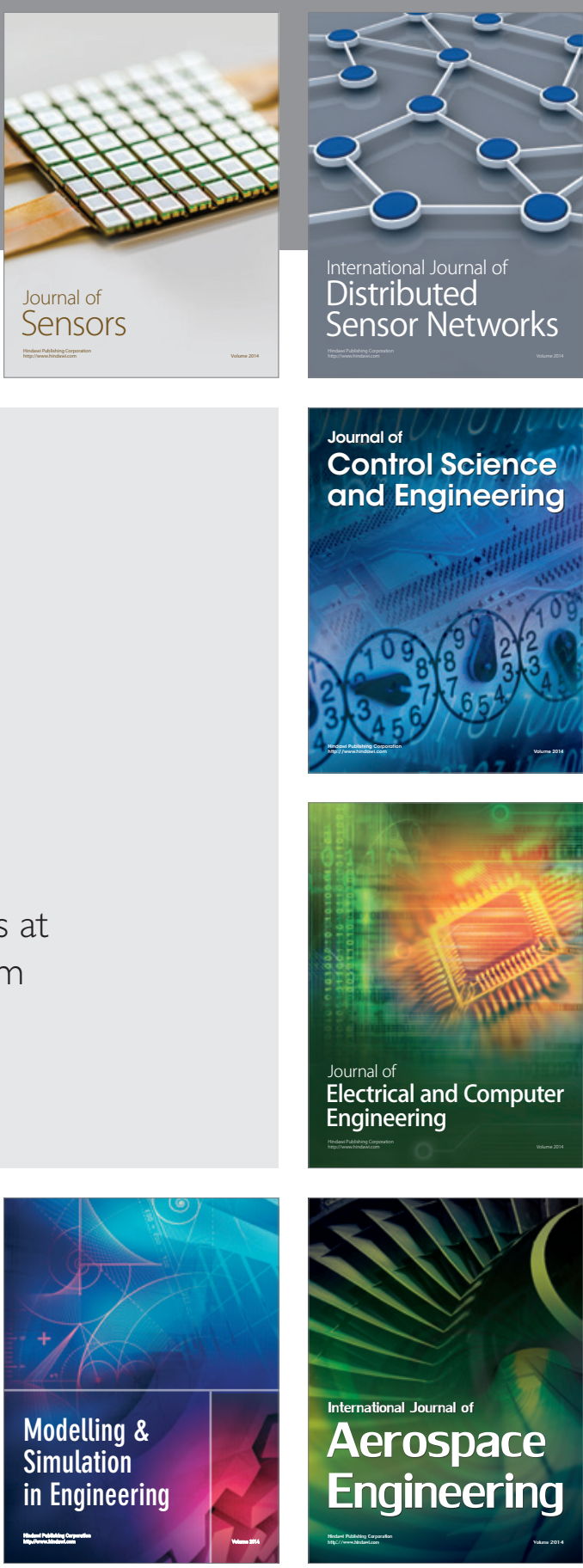

International Journal of

Distributed

Sensor Networks

Journal of

Control Science

and Engineering
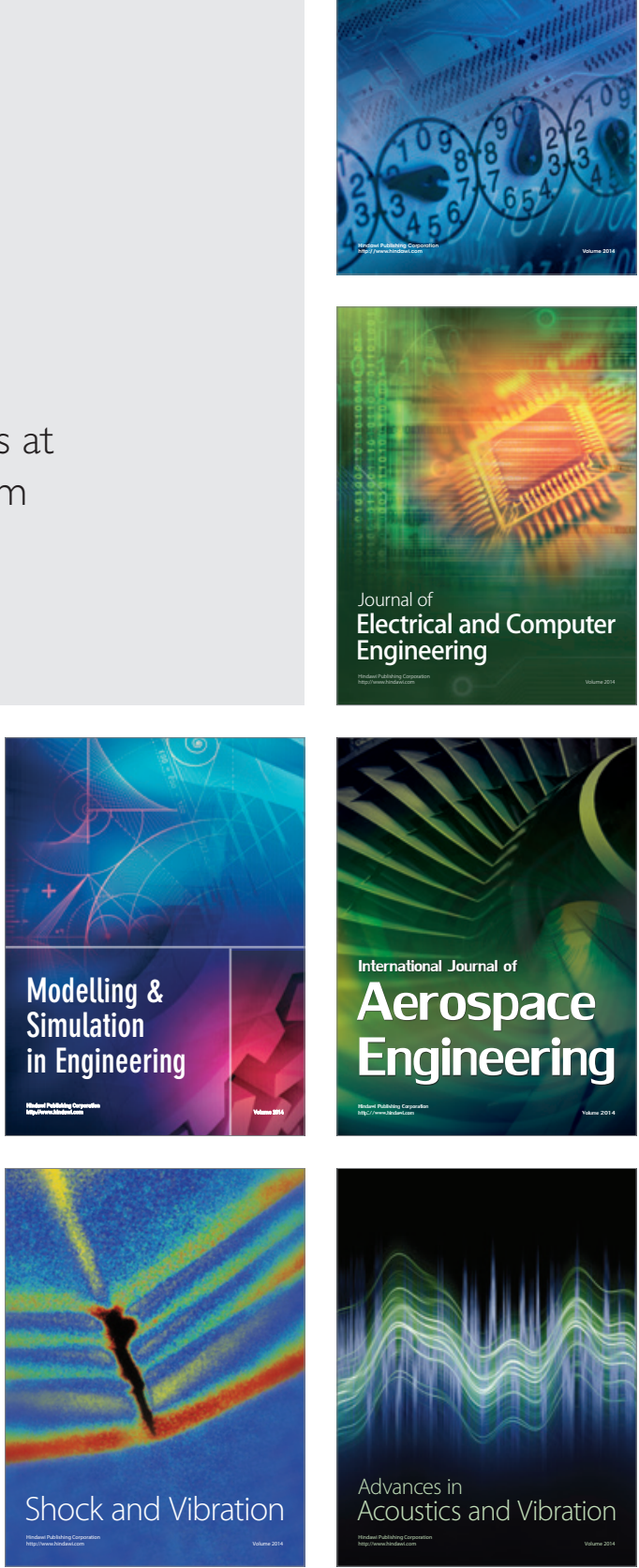